\title{
Energy and macronutrient intake in relation to dental caries incidence in urban black South African preschool children in 1991 and 1995: the Birth-to-Ten study
}

\author{
Jennifer M MacKeown ${ }^{1, *}$, Peter E Cleaton-Jones ${ }^{1}$ and Arthur W Edwards ${ }^{2}$ \\ ${ }^{1} M R C /$ University of the Witwatersrand Dental Research Institute, Johannesburg, Witts, 2050, South Africa \\ ${ }^{2}$ University of the Witwatersrand Computer and Networking Services, Johannesburg, Witts, 2050, South Africa
}

Submitted 19 January 1999: Accepted 19 January 2000

\begin{abstract}
Objective: To study energy and macronutrient intake in relation to dental caries incidence among urban black South African children at the ages of 1 and 5 years. Design and subjects: Food frequency questionnaires and WHO caries diagnostic criteria were used. The study sample of 1639 urban black children with nutrition and dental information from the 1991 and/or 1995 Birth-to-Ten (BTT) Study interceptions comprised true longitudinal $(n=259)$ and cross-sectional $(n=1216$ for 1991 and $n=$ 164 for 1995) subjects. For the longitudinal group true dmfs (decayed, missing, filled surfaces) incidence and average intakes of energy and macronutrients between 1991 and 1995 were calculated.

Setting: South Africa.

Results: Median macronutrient intakes were not significantly different between the cross-sectional and longitudinal samples. Dental caries prevalences at age 1 were $1.2 \%$ and $1.5 \%$ for the cross-sectional and longitudinal samples, respectively. By age 5 these values were $60.4 \%$ and $62.2 \%$, respectively. The median dmfs score at age 1 was 0 . At 5 years this was 2 for all children and 5 for those with caries. Statistical analysis for trend at age 5 showed a significant increase in caries prevalence with increasing energy, carbohydrate and added sugar in the cross-sectional sample only. The only significant changes in dmfs scores were seen for energy and added sugar for the whole sample. The $r$ values between $\log (\mathrm{dmfs}$ incidence +0.3$)$ and the average nutrient log variables were low, and a general linear models analysis showed no statistically significant effects on $\log (\mathrm{dmf}$ incidence +0.3$)$ of any of the log nutrient variables.

Conclusions: For the relationship between macronutrient intake and caries (prevalence and incidence), a cross-sectional and true longitudinal study gave similar results.
\end{abstract}

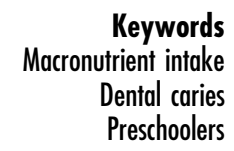

The association between nutrition and dental health has been studied by numerous investigators around the world $^{1-4}$, but dental data have been published from only nine of the 18 countries in subequatorial Africa. Just five of these report nutritional research connected to dental caries, dealing almost exclusively with sucrose intake or fluoride ingestion ${ }^{5}$. Local dietary factors, particularly sugars, have usually been investigated as risk factors for caries, rather than general nutrition ${ }^{6-10}$.

Many factors have to be taken into consideration regarding sugar intake and dental caries, e.g. the amount of sugar consumed, frequency of intake and type of sugar ingested. Over the years the relative importance of these factors has changed. The development of dental caries has been shown to be both negatively ${ }^{11-17}$ and positively ${ }^{18-25}$ related to sugar intake. Even with these contrasting results, convincing evidence suggests that frequency and kind of sugar-containing products consumed correlate with caries better than total amount consumed ${ }^{11,26}$. This paper, however, is limited to the amount consumed and a separate paper will report on the frequency of nutrient intake. Recent reports have attributed a much less important role of carbohydrate; sugar consumption as a single factor no longer affects caries prevalence as much as it did in the past and it is obvious that the role of sugar in the aetiology of dental caries needs to be revised ${ }^{11}$.

Some workers have consequently considered diet in a wider context ${ }^{27,28}$. Studies thus far have shown no relationship of energy intake to caries incidence ${ }^{29,30}$ and carbohydrate intake alone or together with other macronutrients does not fully explain the development of dental caries. This could be because most studies conducted on diet and dental health have been cross-sectional. The Vipeholm ${ }^{31}$ and Hopewood House ${ }^{32}$ studies, and more recently the Michigan study ${ }^{16}$ are the only longitudinal studies that have examined the association between diet and dental caries 
incidence in the permanent dentition, two of which studied only selected groups in institutions ${ }^{31,32}$. Longitudinal studies performed have concentrated mainly on bacteriological rather than dietary variables ${ }^{33}$.

Until 1990 no true longitudinal studies had been conducted on South African preschool children regarding the association between diet and dental caries. The BTT Study is the first South African study to describe the detailed dietary intake of representative South African populations, as well as their dental health. This paper will report on the caries incidence in relation to energy and macronutrient intake (total available carbohydrate, fibre and added sugar) of a cross-sectional and true longitudinal sample of 1- and 5-year-old urban black South African children from the 1991 and 1995 BTT nutrition and dental interceptions. These specific nutrients were used in this paper for comparison with other studies. Information on other macronutrients as well as micronutrients is available from the authors.

\section{Methods}

Prior to the study ethical approval was obtained from the University of the Witwatersrand Committee for Research on Human Subjects. Details of the BTT Study design have been reported elsewhere ${ }^{34-38}$, so only a brief outline is provided.

The BTT Study commenced in 1990. It is a longitudinal observational study designed to follow the biological, environmental, social, economic and psychosocial factors associated with the survival and health of some 2000 urban South African children from the black, 'coloured' (AfricanEuropean-Malay), Indian and white communities over a 10 -year period, living in the Johannesburg/Soweto area in the Gauteng province, previously the Transvaal province, of South Africa. Nutrition and dental interceptions of the study took place in 1991 and 1995 when the children were 1 and 5 years of age, respectively.

\section{Population sample}

Sample size of each community was based on a representative proportional sample of the total South African population according to the 1994 population census ${ }^{39}$. Hence there was a large difference in numbers between the communities for this study. The black community predominates in South Africa and comprises $76 \%$ of the total population ${ }^{39} ; 2-5$-year-olds make up $12 \%$ of this total. This fact, together with available subject numbers made the black community the choice for the current article. The number of subjects in the other groups were too few.

The subject sample reported in this paper consisted of all urban black children participating in the BTT Study that had both nutrition and dental information from the 1991 and/or 1995 interceptions $(n=1639)$. This comprised a true longitudinal sample $(n=259)$ that had nutrition and dental information for both 1991 and 1995, as well as cross-sectional samples that had information for only 1991 $(n=1216)$ or $1995(n=164)$.

\section{Dietary assessment}

After examination of the literature ${ }^{40-46}$, a semiquantitative food frequency questionnaire, validated by Margetts et $a l .{ }^{43}$, appeared to be the most appropriate method for largescale studies such as the BTT Study, in culturally diverse populations. Parents or guardians were asked by multilingual trained interviewers to indicate how frequently these listed food items were consumed. Food items were coded onto computer coding forms using the South African Medical Research Council (MRC) food composition tables and codes ${ }^{47}$. The daily amounts were calculated from the intake frequency and our nutrition programme was applied to determine the mean daily nutrient intake for each individual.

\section{Dental assessment}

Dental caries was recorded according to $\mathrm{WHO}^{48}$ criteria in natural light by calibrated dentists ${ }^{49}$.

\section{Statistical analysis}

The data were analysed with $\mathrm{SAS}^{50}$. The prevalence of caries and dmfs scores were determined within each quartile for energy and each macronutrient. The caries prevalence within each quartile was compared between cross-sectional and longitudinal groups for 1991 and for 1995 with the chi-square test; for dmfs the Kruskal-Wallis non-parametric test was used. A Mantel-Haenszel chisquare test for trend was used to examine the caries prevalence from first to last quartile within cross-sectional and longitudinal groupings within each year. The KruskalWallis test was used to examine for significant differences between mean dmfs scores for each quartile of energy and macronutrient intake within each study grouping.

For the longitudinal component of the study the true caries incidence was calculated for each child by subtracting the dmfs score at 1991 from that at 1995. For energy and the macronutrient intakes the average of the intakes at both years was calculated for each child.

The distribution of dmfs incidence was highly skewed with many of the scores being zero (Table 1) which indicated a need to transform the data for statistical analysis. Transformation to exact normality of such ordinal data is not possible; but a key feature of normality - zero skewness - was achieved by a systematic search among transformations of the form $\log (\mathrm{dmfs}$ incidence $+k)$. The $k$ achieving zero skewness was 0.3 . The energy and nutrient

Table 1 Frequency of dmfs incidence for the longitudinal group of urban black South African children $(n=259)$

\begin{tabular}{lcc}
\hline dmfs incidence & Frequency & $\%$ \\
\hline$\leqslant 0$ & 2 & 0.8 \\
0 & 96 & 37.1 \\
$1-4$ & 74 & 28.5 \\
$5-9$ & 55 & 21.2 \\
$\geqslant 10$ & 32 & 12.4 \\
\hline
\end{tabular}


information was also not normally distributed but since there were no zero values a simple log transformation was done for each child. Two statistical analyses were done. Pearson correlations were calculated between the $\log (\mathrm{dmfs}$ incidence +0.3$)$ and the $\log$ of average energy and each nutrient variable, and, secondly a general linear model analysis was performed with $\log (\mathrm{dmfs}$ incidence + 0.3 ) as the dependent variable and the log of the average energy and macronutrient intakes as the independent variables. The critical level for statistical significance was set at $P<0.05$.

\section{Results}

Cross-sectional sample median macronutrient intakes were almost the same as in the longitudinal sample (Table 2). Median intakes of energy and total available carbohydrate were 3 times greater at age 5 years than at age 1 for both the cross-sectional and longitudinal samples, while for fibre and added sugar intakes at age 5 years were three and four times greater than at age 1, respectively. For all nutrients the mean intakes were always greater than the median values. The KruskalWallis test showed no significant differences in energy and macronutrient intakes between the cross-sectional and longitudinal samples.

The dental caries prevalences at age 1 were very low as might be expected, being $1.2 \%$ and $1.5 \%$ for the crosssectional and longitudinal samples, respectively, but by age 5 these values had increased to $60.4 \%$ and $62.2 \%$ for the respective groups. Median dmfs scores for all the children at age 1 was 0 . By 5 years this had increased to 2 for all children and 5 for those individuals with caries only.

Because of the extremely low caries prevalence among the 1 year olds no statistical tests were done on this group. All further analysis was carried out on the 5 year olds (1995 sample) only. Statistical analysis for trend at age 5 showed a significant increase in the prevalence of caries with increasing energy $\left(x^{2}=7.91, P=0.05\right)$, total available carbohydrate $\left(x^{2}=3.95, P=0.01\right)$ and added sugar $\left(x^{2}=\right.$ 6.12, $P=0.01$ ) in the cross-sectional sample, but no significant changes were seen in the longitudinal sample.

The only significant changes in dmfs scores were seen for energy $\left(x^{2}=8.00, P=0.05\right)$ and added sugar $\left(x^{2}=14.15\right.$, $P=0.003)$ for all the children in the cross-sectional sample, with no significant changes in the longitudinal sample. No significant changes were found in $\mathrm{dmfs}$ scores for individuals with caries only in the cross-sectional or longitudinal samples, therefore the results for these individuals are not shown in this manuscript.

Table 3 shows mean energy and macronutrient intakes in 1991 and 1995 as well as the average intakes of the two periods. The dmfs incidence in Table 1 clearly shows skewing towards the lower values. The negative incidence in two children indicates either a misdiagnosis or a reversal of an earlier caries lesion.

The $r$ values between $\log (\mathrm{dmfs}$ incidence +0.3$)$ and the log nutrient variables were energy 0.03 , total available carbohydrate 0.001 , fibre -0.008 and added sugar -0.008 . All of these values are very low and none were statistically significant. The general linear models analysis showed no statistically significant effects on dmfs incidence of any of the nutrient variables.

\section{Discussion}

Dental caries prevalence rates differed significantly as energy and macronutrients increased in the cross-sectional

Table 2 Daily energy and macronutrient intake (median, mean and SD) for urban black South African children. Kruskal-Wallis testing results are shown $(\mathrm{df}=1)$

\begin{tabular}{|c|c|c|c|c|}
\hline & \multicolumn{2}{|c|}{1991 (1 year olds) } & \multicolumn{2}{|c|}{1995 (5 year olds) } \\
\hline & Cross-sectional & Longitudinal & Cross-sectional & Longitudinal \\
\hline Number & 1216 & 259 & 164 & 259 \\
\hline $\begin{array}{l}\text { Energy (cal) } \\
\text { Median } \\
\text { Mean } \\
\text { SD }\end{array}$ & $\begin{array}{l}\quad x^{2}=2.6 \\
707 \\
812 \\
449\end{array}$ & $\begin{array}{r}=0.11 \\
671 \\
779 \\
424\end{array}$ & $\begin{array}{l}x^{2}=1.8 \\
1950 \\
2039 \\
631\end{array}$ & $\begin{array}{r}0.17 \\
2029 \\
2096 \\
511\end{array}$ \\
\hline $\begin{array}{l}\text { Total available carbohydrate }(\mathrm{g}) \\
\text { Median } \\
\text { Mean } \\
\text { SD }\end{array}$ & $\begin{array}{l}x^{2}=1.5 \\
79 \\
91 \\
49\end{array}$ & $=0.22 \begin{array}{r}76 \\
89 \\
51\end{array}$ & $\begin{array}{l}x^{2}=1.8 \\
245 \\
257 \\
90\end{array}$ & $\begin{array}{r}0.17 \\
258 \\
260 \\
62\end{array}$ \\
\hline $\begin{array}{l}\text { Fibre }(g) \\
\quad \text { Median } \\
\text { Mean } \\
\text { SD }\end{array}$ & $\begin{array}{l}x^{2}=0.0 \\
5 \\
5 \\
2\end{array}$ & $=0.84$ & $\begin{array}{l}x^{2}=1.86 \\
16 \\
17 \\
5\end{array}$ & $\begin{array}{rr}=0.17 & \\
& 17 \\
18 \\
5\end{array}$ \\
\hline $\begin{array}{l}\text { Added sugar }(\mathrm{g}) \\
\text { Median } \\
\text { Mean } \\
\text { SD }\end{array}$ & $\begin{array}{l}x^{2}=0 . \\
15 \\
17 \\
13\end{array}$ & $=0.48 \begin{array}{r} \\
14 \\
17 \\
14\end{array}$ & $\begin{array}{l}x^{2}=1.6 \\
67 \\
77 \\
55\end{array}$ & 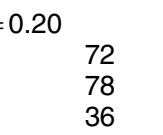 \\
\hline
\end{tabular}


Table 3 Mean daily energy, macronutrient intake and dmfs incidence for the longitudinal group of urban black South African children ( $n=259)$

\begin{tabular}{|c|c|c|c|c|c|c|c|c|}
\hline \multirow[b]{2}{*}{ Variable } & \multicolumn{2}{|c|}{1991 (1 year olds) } & \multicolumn{2}{|c|}{1995 (5 year olds) } & \multicolumn{2}{|c|}{$\begin{array}{l}\text { Average intake } \\
\text { of both years }\end{array}$} & \multicolumn{2}{|c|}{ dmfs incidence } \\
\hline & Mean & SD & Mean & SD & Mean & SD & Mean & SD \\
\hline Energy (cal) & 779 & 424 & 2096 & 511 & 1438 & 331 & & \\
\hline Total available carbohydrate $(\mathrm{g})$ & 89 & 51 & 260 & 62 & 174 & 41 & & \\
\hline Fibre $(\mathrm{g})$ & 5 & 3 & 18 & 5 & 12 & 3 & & \\
\hline Added sugar (g) & 17 & 14 & 78 & 36 & 48 & 19 & & \\
\hline dmfs & 0 & 0 & 4 & 6 & & & 4 & 6 \\
\hline
\end{tabular}

sample only, but was less evident with dmfs scores. This was probably due to the mathematical effect of larger sample size in the cross-sectional sample. However, this study enabled a true longitudinal examination of caries incidence in relation to energy and macronutrient intake. The nutrient intake of the children increased from 1991 to 1995 , and there was very little caries progression in $62 \%$ of the same individuals. Statistical analysis showed no relationship between caries incidence and average nutrient consumption over 4 years in this true longitudinal cohort.

Many publications have assessed the influence of diet on dental caries in the permanent dentition, but dietary influences on primary dentition caries have not been studied widely ${ }^{25,51}$, not in large samples ${ }^{25}$, and particularly not in longitudinal studies ${ }^{24}$. In addition no South African study has been able to compare the association between diet and dental caries incidence in cross-sectional and longitudinal subjects in the same longitudinal cohort. The information from this study is thus unique and true comparisons with other studies can therefore not be made.

Studies on the association between diet and dental caries have used dietary records ${ }^{25,51}$ and/or 24-hour recalls $^{14,24}$ to assess dietary intake. No study, however, has used a semiquantitative food frequency questionnaire covering the overall general dietary intake of the study population, although a food frequency questionnaire with limited selected food items has been used ${ }^{3}$. According to Willett ${ }^{52}$, food frequency questionnaires have now become the primary method for measuring dietary intake in epidemiological studies. The underlying principle of the food frequency approach is that average long-term diet is the conceptually important exposure rather than intake on a few specific days ${ }^{53}$. This is particularly important when studying the relationship between diet and dental health as caries develop over a period of time and caries incidence is dependent on long-term dietary intake rather than present intake. The semiquantitative food frequency questionnaire was the method of choice for this study.

The dmfs scores and caries incidence of the present study have shown both similar and contrasting differences with reported studies in other countries as well as in South Africa itself. A longitudinal study on dental caries incidence in the Netherlands in 2-5-year-old children showed mean dmfs scores to be 2.54, 1.17 and 1.00, respectively, for 5-year-old children who were $47.8 \%$, $71.9 \%$ and $75.9 \%$ caries free according to three evidential categories for carious lesions ${ }^{24}$. These results were low in comparison to other studies conducted in the Netherlands $s^{54,55}$ that found about $60 \%$ of 5 -year-old children to be caries free, but the dmfs scores to be twice as high. The mean dmfs scores in Roeters ${ }^{24}$ study were, however, lower than those reported in our study (mean dmfs 4) for 5-year olds, but compare favourably with those reported by Truin et al..$^{55}$. Approximately $40 \%$ of the 5 -year-old children in the present study were caries free, lower than that reported for 5 year olds in the Netherlands. However, the 1992/93 National Diet and Nutrition Survey ${ }^{25}$ of children in Britain aged 1.5-4.5 years showed that $17 \%$ of all the children had some caries experience that greatly increased with age affecting 30\% of the 3.5-4.5 year olds, with approximately $70 \%$ of the children being caries free. The percentage of caries-free individuals in that study is considerably higher than for urban black children of approximately the same age in South Africa. In the USA ${ }^{51}$ mean dfs scores were 4.0 for the total sample of children aged 2-6 years, which compares favourably with the mean dmfs scores for the 1995 sample in the present study. South African studies ${ }^{5}$ have shown mean dmfs scores in urban black 4- and 5-year-old children to be higher than the present study but the caries prevalence to be similar at around $60 \%$.

In the BTT Study there was no significant difference in caries prevalence or dmfs scores between the longitudinal and cross-sectional children aged 1 year. With regard to caries the longitudinal group of BTT children were representative of the whole group of urban black 1 year olds. The prevalence of caries at 1 year in the longitudinal group was low as was the mean dmfs score; the only other study in South Africa ${ }^{56}$ on urban 1-year-old children in the same Soweto area 10 years previously also reported low caries rates with a prevalence of $5.1 \%$ and mean dmfs score of 0.2 . There is no reason to believe that the BTT longitudinal group differed from other urban black 1-yearold children.

Diet, in particular sugar intake in association with dental health, has shown both significant ${ }^{18-25}$ and non-significant $^{12-14,16,17}$ roles in caries incidence. Studies in Dunedin ${ }^{4}$, South America ${ }^{57}$ and South Africa ${ }^{12,13,58}$ have also shown no significant associations between the intake of sugar 
(amount, type or frequency), refined carbohydrate and dental caries incidence among preschool children. The importance of diet in caries incidence has, however, been demonstrated in other studies, with regard to total amount consumed $^{22}$, as well as the frequency of intake ${ }^{3,31,32,59}$. It should be noted that the correlation between diet and caries prevalence will be low when caries prevalence is low and the difference in diet habits is small. Crosssectional data in South Africa showed sugar consumption between 1976 and 1984 to remain relatively constant at 63-70 $\mathrm{g} \mathrm{day}^{-1}$ among 5-year-old urban black South African children, but dental caries prevalence to worsen during this time as did the mean $\mathrm{dmft}$ scores ${ }^{15,22,60,61}$. This was, however, in keeping with worldwide trends of dental caries reducing in developed populations and increasing in developing populations. By the 1990s the situation among the urban black community had changed. Sugar intake, although assessed by different assessment methods, had increased to about $78 \mathrm{~g} \mathrm{day}^{-1}$ by 1995 in the present study, but caries prevalence had decreased with approximately $60 \%$ of the 5-year-old urban black children having caries compared to approximately 70\% between 1976 and 1978 and $78 \%$ in $1984^{22}$.

With regard to other nutrients besides sugar, Marques and Messer $^{51}$ studied the nutrient intake and dental caries incidence in 2-6-year-old children in the USA. The association of 15 nutrients in addition to sugar were assessed. No association was apparent between dental caries and the intake of total sugar consumption or $\mathrm{Ca}: \mathrm{P}$ ratio. Except for a positive association with iron and a negative association with magnesium, caries were not associated with any specific nutrient. Dental caries prevalence among 4- and 5-year-old South African children from all communities was constant for protein intake, but higher in those children in the upper quartile for energy, fat and total available carbohydrate, the difference being statistically significant for all nutrients except protein. A similar contrast was made for dmfs scores. Among the children for energy, fat and total available carbohydrate and sugar intake, those in the upper quartile had dmfs scores of about twice those in the lower quartile. These were statistically significant for all groupings ${ }^{5}$. The present study too showed a significant increase in caries as energy, total available carbohydrate and added sugar increased in the cross-sectional sample. In contrast, energy intake among 11-year-old black children in Namibia and KwaZulu was not associated with dental caries in the permanent dentition ${ }^{30}$.

It is clear from this discussion that studies ${ }^{12,57,62-64}$ among South African preschool children have indicated some unexpected and contrasting patterns of dental caries between the communities. In particular, the unusual association of low sucrose intake with relatively high caries among rural black South African preschool children $^{62}$. The results of this study are therefore specific to preschool children from the urban black community and cannot be extrapolated to other communities, populations or age groups.

This study enabled both a cross-sectional and true longitudinal examination of caries (prevalence and incidence) in relation to energy and macronutrient intake. For the relationship between macronutrient intake and dental caries prevalence rates in urban black South African children minimal differences were found between the cross-sectional and longitudinal groups, probably due to subject numbers. Within the longitudinal group there was no relationship between caries incidence and average nutrient consumption. Therefore, for the relationship between macronutrient intake and caries (prevalence and incidence) a cross-sectional and true longitudinal study among urban black South African preschool children gave very similar results.

\section{References}

1 Richardson AS, Boyd MA, Conry F. A correlation study of diet, oral hygiene and dental caries in 457 Canadian children. Community Dent. Oral Epidemiol. 1977; 5: 22730 .

2 Persson L-A, Stecksens-Blicks C, Holm A-K. Nutrition and health in childhood: causal and qualitative interpretations of dental caries. Community Dent. Oral Epidemiol. 1984; 12: 390-7.

3 Majem LS, Closas RG, Manau C, Cuenca E, Krasse B. Dietary habits and dental caries in a population of Spanish schoolchildren with low levels of caries experience. Caries Res. 1993; 27: 488-94.

4 Guha-Chowdury N. Diet of 3 and 4 year olds in Dunedin: relevance to dental caries. Pacific Health Dialog. 1996; 3: $15-19$.

5 Cleaton-Jones PE. Nutrition and dental caries in South Africa. Int. Dent. J. 1996; 46 (Suppl. 1): 374-80.

6 Burt BA, Eklund SA, Morgan KJ, et al. The effects of sugars intake and frequency of ingestion on dental caries increment in a three year longitudinal study. J. Dent. Res. 1988; 67: 1422-9.

7 Holm A-K, Blomquist K, Crossner C-G, Grahnen H, Samuelson G. A comparative study of oral health as related to general health, food habits and socio-economic conditions of 4-year-old Swedish children. Community Dent. Oral Epidemiol. 1975; 3: 34-9.

8 Ravald N, Birkhed D. Factors associated with active and inactive root caries in patients with periodontal disease. Caries Res. 1991; 25: 377-84.

9 Sreebny LM. Sugar and human dental caries. World Rev Nutr. Diet. 1982; 40: 19-65.

10 Walker ARP, Cleaton-Jones PE. Sugar intake and dental caries: where do we stand? J. Dent. Child. 1989; 56: 30-5.

11 Harel-Raviv M, Laskaris M, Chu KS. Dental caries and sugar consumption into the 21st century. Am. J. Dent. 1996; 9: 184-90.

12 Richardson BD, Cleaton-Jones PE, McInnes PM, Rantsho JM, Pieters L. Total sucrose intake and dental caries in black and in white South African children of 1-6 years. Part II. Dental caries and sucrose intake. J. Dent. Assoc. South Afr. 1978; 33: 539-44.

13 Richardson BD, Cleaton-Jones P. Sucrose intake patterns of black and white preschool children and their role in dental health. J. Diet. Home Econ. 1979; 7: 24-8.

14 Cleaton-Jones PE, Richardson BD, Sinwel RE, Rantsho JM, Granath L. Dental caries, sucrose intake and oral hygiene in 
5-year old South African Indian children. Caries Res. 1984; 18: $472-7$.

15 Richardson BD, Cleaton-Jones P, Sinwel RE, Rantsho JM. Trends in sugar intake. Do these parallel changes in caries prevalence among South African preschoolchildren? Community Dent. Oral Epidemiol. 1984; 12: 140-4.

16 Burt BA, Szpunar SM. The Michigan study: the relationship between sugars intake and dental caries over three years. Int. Dent. J. 1994; 44: 230-40.

17 Silver DH. A longitudinal study of infant feeding practice, diet and caries, related to social class in children aged 3 and 8-10 years. Br. Dent. J. 1987; 163: 296-300.

18 Kleemola-Kujala E, Rasanen L. Relationship of oral hygiene and sugar consumption to risk of caries in children. Community Dent. Oral Epidemiol. 1982; 10: 224-33.

19 Faine MP, Oberg D. Snacking and oral health habits of the Washington state WIC children and their caregivers. J. Dent. Child. 1994; 16: 350-5.

20 Commission on Oral Health, Research and Epidemiology (CORE). The prevention of dental caries and periodontal disease. Int. Dent. J. 1984; 34: 141-58.

21 Grytten J, Rossow I, Holst D, Steele L. Longitudinal study of dental health behaviors and other caries predictors. Community Dent. Oral Epidemiol. 1988; 16: 356-9.

22 Cleaton-Jones PE, Richardson BD, Winter GB, Sinwel RE, Rantsho JM, Jodaikin A. Dental caries and sucrose intake in five South African preschool groups. Community Dent. Oral Epidemiol. 1984; 12: 381-5.

23 Holbrook WP, Kristinsson MJ, Gunnarsdottir S, Briem B. Caries prevalence, Streptococcus mutans and sugar intake among 4-year-old urban children in Iceland. Community Dent. Oral Epidemiol. 1989; 17: 292-5.

24 Roeters J, Burgersdijk R, Truin G-J, Vanthof M. Dental caries and its determinants in 2- to 5-year old children. J. Dent. Child. 1995; 62: 401-8.

25 Moynihan PJ, Holt RD. The National Diet and Nutrition Survey of 1.5 to 4.5 year old children: summary of the findings of the dental survey. Br. Dent. J. 1996; 181: 32832.

26 Ziesenitz SC. Dental health and sugar consumption in Germany. Ernabrungs Umschau. 1998; 45: 240.

27 Lachapelle D, Couture C, Brodeur J-M, Sevigny J. The effects of nutritional quality and frequency of consumption of sugary foods on dental caries increment. Can. J. Public Health 1990; 18: 370-5.

28 Willett W, Stamper MJ. Total energy intake: implications for epidemiological analysis. Am. J. Epidemiol. 1986; 124: 1727.

29 Alvarez JO, Eguren JC, Caceda J, Navia J. The effect of nutritional status on the age distribution of dental caries in the primary dentition. J. Dent. Res. 1990; 69: 1564-6.

30 MacKeown JM, Cleaton-Jones PE, Hargreaves JA. Energy intake, dental caries and periodontal disease in 11-year-old black children in two regions of Southern Africa: KwaZulu and Namibia. Community Dent. Oral Epidemiol. 1995; 23: 182-6.

31 Gustafsson BE, Quensel C-E, Lanke LS, et al. The Vipeholm dental caries study. The effect of different levels of carbohydrate intake on caries activity and 436 individuals observed for 5 years. Acta Odontol. Scand. 1954; 11: 232364.

32 Harris R. Biology of the children of Hopewood House, Bowral, Australia. Four observations on dental caries experience extending over 5 years (1957-61). J. Dent. Res. 1963; 42: 1387-99.

33 Alaluusua S, Renkonen OV. Streptococcus mutans establishment and dental caries experience in children from 2 to 4 years old. Scand. J. Dent. Res. 1983; 91: 453-7.

34 Fonn S, De Beer M, Kgamphe JS, et al. Birth to Ten: pilot studies to test the feasibility of a birth cohort study investigating effects of urbanisation in South Africa. South Afr. Med.J. 1991; 79: 449-54.

35 Yach D, Cameron N, Padayachee GN, Wagstaff LA, Richter L, Fonn S. Birth to Ten: child health in South Africa in the 1990s. Rationale and methods of a birth cohort study. Paediatr. Perinatal. Epidemiol. 1991; 5: 211-33.

36 Anderson A, Richter LM. Birth to Ten: error detection and correction in a longitudinal address database. South Afr. J. Epidemiol. Infect. 1994; 9: 16-19.

37 Richter LM, Yach D, Cameron N, Griesel RD, De Wet T, Anderson A. Enrolment into Birth to Ten (BTT): sample and population characteristics. Paediatr. Perinatal. Epidemiol. 1995; 9: 109-20.

38 MacKeown JM, Cleaton-Jones PE, Edwards AW, TurgeonO'Brien H. Energy, macro- and micronutrient intake of 5year-old urban black South African children in 1984 and 1995. Paediatr. Perinatal. Epidemiol. 1998; 12: 297-312.

39 Steenkamp HA. Population Estimates for the RSA by Magisterial District and Province, 1994. Research Report No. 212. Pretoria: Bureau of Market Research, University of South Africa, 1994.

40 Block G. A review of validations of dietary assessment methods. Am. J. Epidemiol. 1982; 115: 492-505.

41 Chu SY, Kolonel RN. A comparison of frequency and quantitative dietary methods for epidemiological studies of diet and disease. Am. J. Epidemiol. 1984; 119: 323-34.

42 Block G, Dresser CM, Hartman AM, Carrol MD. Nutrient sources in the American diet: quantitative data from the NHANES II survey. II. Macronutrients and fats. Am. J. Epidemiol. 1985; 122: 27-40.

43 Margetts BM, Cade JE, Osmond C. Comparison of a food frequency questionnaire with a diet record. Int.J. Epidemiol. 1989; 18: 868-73.

44 Borelli R. Collection of food intake data: a reappraisal of criteria for judging the methods. Br. J. Nutr. 1990; 63: 41117.

45 Thompson RL, Margetts BM. Comparison of a food frequency questionnaire with a 10-day weighed record in cigarette smokers. Int. J. Epidemiol. 1993; 22: 824-33.

46 Hankin JH, Wilkens LR. Development and validation of dietary assessment methods for culturally diverse populations. Am. J. Clin. Nutr. 1994; 59 (Suppl. 1): S198-200.

47 Langenhoven ML, Kruger M, Gouws E, Faber M. Research Institute for Nutritional Diseases (RIND) Food Composition Tables, 3rd edn. Cape Town: South African Medical Research Council, 1991

48 World Health Organization. A Guide to Oral Health Epidemiological Investigations, 3rd edn. Geneva: World Health Organization, 1987; 6-8.

49 Cleaton-Jones PE, Hargreaves JA, Fatti LP, Chandler HD, Grossman ES. Dental caries diagnosis calibration for clinical field surveys. Caries Res. 1989; 23: 195-9.

50 SAS Institute Inc. SAS/STAT User's Guide. Version 6, 4th edn, Vol. 1. Cary, NC: SAS Institute, 1989.

51 Marques AP, Messer LB. Nutrient intake and dental caries in the primary dentition. Paediatr. Dent. 1992; 21: 314-21.

52 Willett W. Nutritional Epidemiology. New York: Oxford University Press, 1990.

53 Sempos CT. Invited commentary: some limitations of semiquantitative food frequency questionnaires. Am. J. Epidemiol. 1992; 135: 1127-32.

54 Frencken JE, Kalsbeek H, Verrips GH. Has the decline in dental caries been halted? Changes in caries prevalence among 6 and 12-year old children in Friesland. 1973-1988. Int. Dent. J. 1990; 40: 225-30.

55 Truin GJ, Konig KG, De Vries HCB, Mulder J, Plasschaert AJM. Trends in caries prevalence in 5, 7 and 11-year old school children in The Hague between 1969 and 1989. Caries Res. 1991; 25: 462-7.

56 Cleaton-Jones PE, Hargreaves JA, Roberts G, Williams SDL, 
Leidal TI. The dmfs and dmft of young South African children. Community Dent. Oral Epidemiol. 1989; 17: 38-40.

57 Morales A, Guerrero S, Arquerson N. Cariogenic food consumption and dental caries in school children with temporary and deciduous dentition. Rev. Chil. Nutr. 1994; 22: $105-8$.

58 Richardson BD, Rantsho JM, Pieters L, Cleaton-Jones PE. Total sucrose intake and dental caries in black and in white South African children of 1-6 years. Part I. Sucrose intake. J. Dent. Assoc. South Afr. 1978; 33: 533-7.

59 Holbrook WP, Arnadottir IB, Takazoe I, Birkhed D, Frostell G. Longitudinal studies of caries cariogenic bacteria and diet in children just before and after starting school. Eur. J. Oral Sci. 1995; 103: 42-5.

60 Cleaton-Jones PE, Richardson BD, Setzer S, Williams S.
Primary dentition caries trends, 1976-1981, in four South African populations. Community Dent. Oral Epidemiol. 1983; 11: 312-16.

61 Richardson BD, Cleaton-Jones P. Sugar, snacks, fluoride and dental caries in RSA preschool children: an overview. J. Dent. Assoc. South Afr. 1986; 41: 611-13.

62 Cleaton-Jones PE, Richardson BD, Rantsho JM. Dental caries in rural and urban black preschool children. Community Dent. Oral Epidemiol. 1978; 6: 135-8.

63 Cleaton-Jones PE, Richardson BD, McInnes PM. Dental caries in coloured and Indian children aged $1-5$ years. J. Dent. Assoc. South Afr. 1981; 36: 61-3.

64 Cleaton-Jones PE, Richardson BD, McInnes PM, Fatti LP. Dental caries in South African white children aged 1-5 years. Community Dent. Oral Epidemiol. 1978; 6: 78-81. 